\title{
PHYSIOLOGIC REQUIREMENTS FOR AUXILIARY LIVER
}

\section{HOMOTRANSPLANTATION}

\author{
T. L. MARCHIORO, M.D., F.A.C.S., Denver, Colorado, K. A. PORTER, M.D., D.Sc., \\ London, England, T. C. DICKINSON, M.D., T. D. FARIS, M.D., and \\ T. E. STARZL, M.D., F.A.C.S., Denver, Colorado
}

FOR HEPATIC homotransplantation, two general types of operative procedures are available. One, which would be applicable for the treatment of malignant disease of the liver, consists of removal of the recipient's own organ and replacement with a hepatic homograft. The other variety of operation, which was first described in principle by Welch and Goodrich and their associates (Fig. 1A), is designed for the treatment of patients with hepatic failure due to benign disease, such as cirrhosis, and does not involve recipient hepatectomy.

There would be important advantages in performing hepatic homotransplantation without recipient hepatectomy. The formidable task of extirpation of a liver would be avoided. In addition, any remaining function of the diseased host liver would be retained so that immediate total dependence upon the homograft would not be necessary. In spite of these appealing features, the disconcerting observation was recently made $(12,13)$ that there was very marked and rapid reduction in the size of auxiliary homografts which were placed by Welch's technique into dogs receiving immunosuppressive agents, the diminution of homograft mass beginning within 2 weeks. Different explanations for this phenomenon were suggested, including the possibility that there was competition for nutritional substrate by the two livers with the result that the dog's

From the Department of Surgery, University of Colorado Medical School and the Denver Veterans Administration Hospital, Denver, and the Department of Pathology, St. Mary's

Aided by Grants A-6283, A-6344, HE 07735, AM 07772, AI

01452 and FR 00051 from the U. S. Public Health Service and by a grant from the Medical Research Council of Great Britain. own organ, which received the alimentary venous flow first, was operating at a physiologic advantage in comparison to the ectopically placed homograft.

In the present study, the role of portal venous flow in affecting the well-being of the homograft and the host's own liver was studied by a series of experiments designed to allow one or the other liver to have primary access to the splanchnic venous flow. The consequence of the study has been to clarify those physiologic factors which appear to be requisite for the successful employment of auxiliary liver homografts.

\section{METHODS}

Twenty-six mongrel dogs, weighing 11.3 to 24.1 kilograms, were used for recipients. The experiment was carried to completion in 15 of these animals, and this group constitutes the basis for the present report. Liver homografts were obtained from healthy animals weighing from 0.5 to 5 kilograms less than the recipient. All operative procedures were performed under pentobarbital anesthesia.

Each recipient animal was treated with azathioprine, 2 to 8 milligrams per kilogram per day, as the sole immunosuppressive agent. This drug was administered orally except during the immediate postoperative periods, at which time the intravenous route was used. As soon as possible the animals were returned to standard kennel feedings. In 3 of the dogs, removal of their own livers was carried out 61 to 77 days after homotransplantation, by a method which preserves the intrahepatic inferior vena cava 


\section{Surgery, Gynecology \& Obstetrics · July 1965}

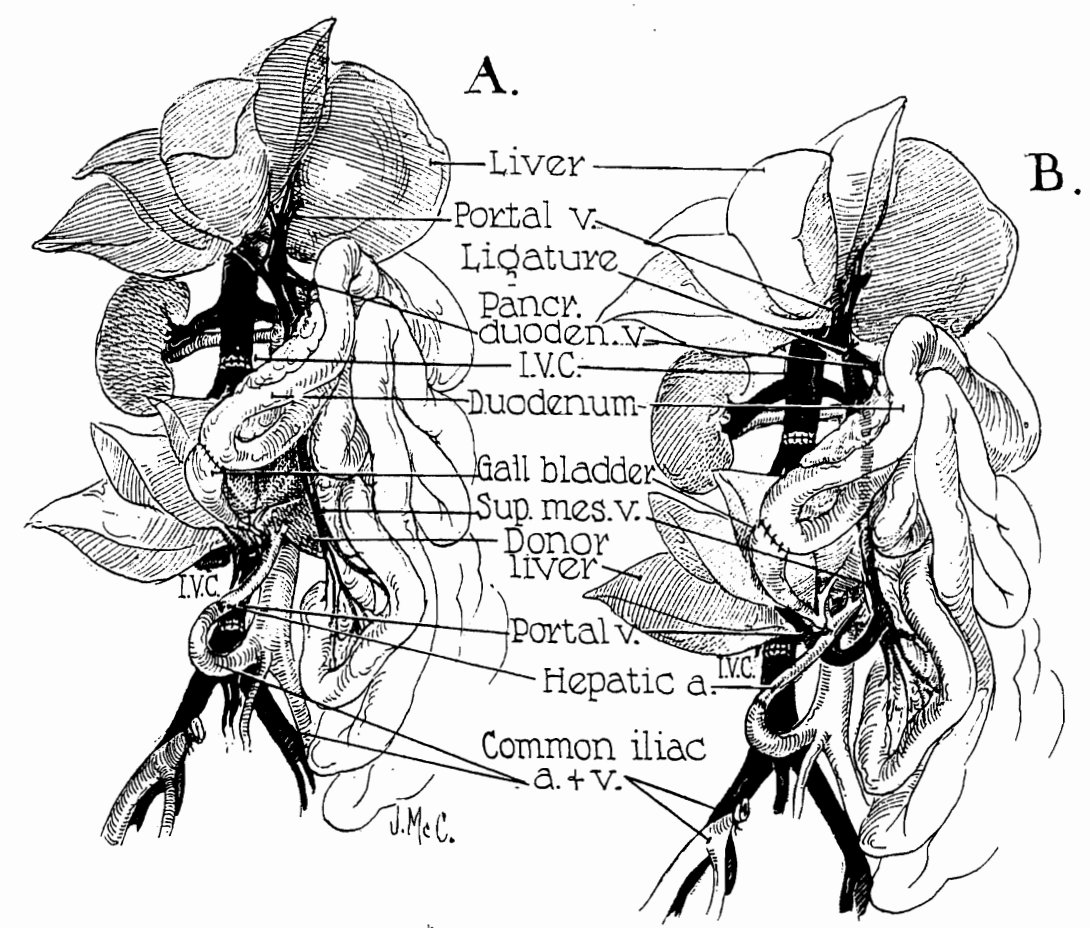

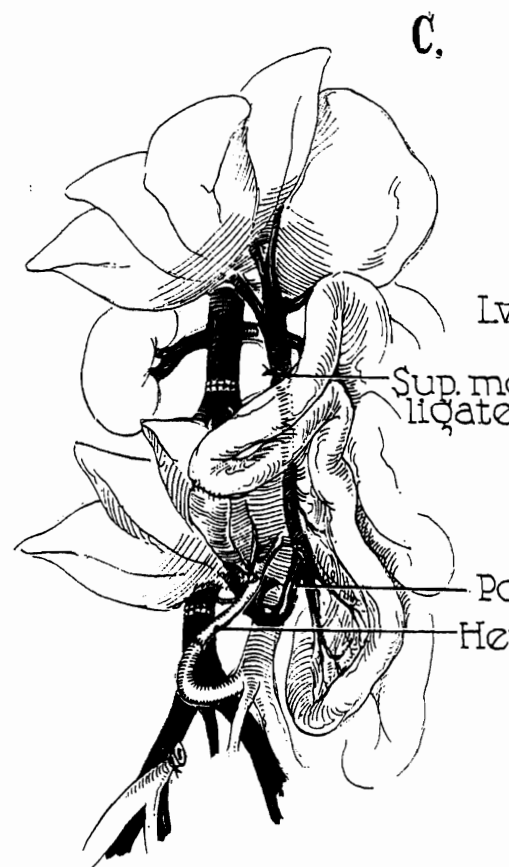

FIg. 1. Experimental protocols for auxiliary hepatic homotransplantation. A, Previously reported modification of Welch-Goodrich hepatic homotransplantation. Homograft undergoes rapid atrophy and diminution in size. Portal blood flow is from the systemic venous system. B, Preparation of group 1 dogs in present study. Nonhepatic splanchnic flow is diverted through the homograft. With this preparation, the homograft retains its size and the animal's own liver undergoes shrinkage. It is

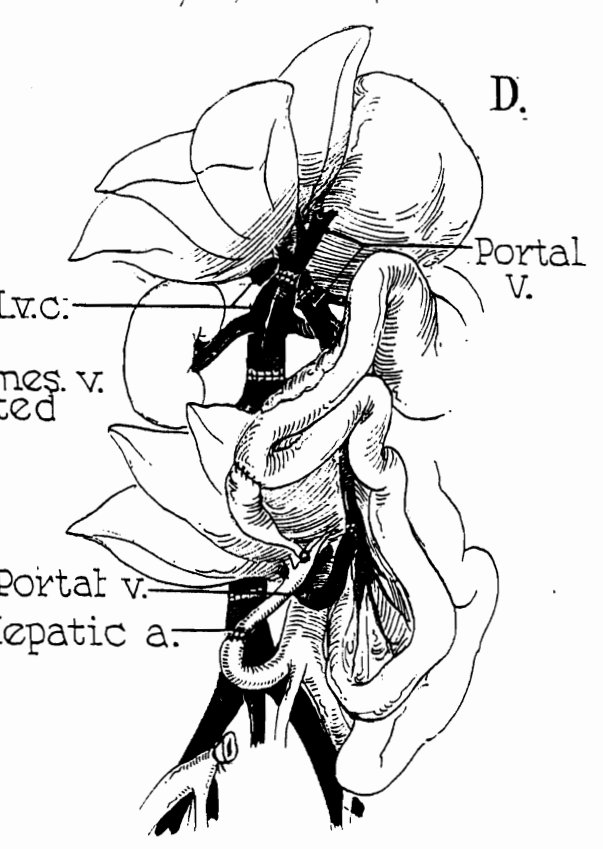

usually more convenient to bring the hepatic artery be. hind, rather than in front of, the portal vein as depicted. C, Superior mesenteric vein is ligated below the splenic vein, partitioning nonhepatic splanchnic flow between the autologous liver and the homograft. Homograft shrinkage occurs but more variably (group 2). D, Auxiliary homotransplantation in group 3 . The host liver is vascularized as with the portacaval transposition of Child. 
(12). For these dogs, azathioprine was continued; and, in addition, radioactive sulfur methionine was administered intravenously to 1 dog every 5 days after hepatectomy, each dose containing 88 microcuries of radioactive sulfur in approximately $1.8 \mathrm{milli}$ grams of methionine. No continuous infusions of glucose were used after hepatectomy and the pre-existing high protein diet was resumed as quickly as possible.

Postoperative hematologic studies were obtained daily in order to determine the safe dose of azathioprine. Biochemical determinations were performed twice a week. These consisted of measurement of serum bilirubin by the Malloy-Evelyn technique, alkaline phosphatase by the Bodansky method, serum glutamic oxalacetic transaminase and serum glutamic pyruvic transaminase in Sigma-Frankel units, and fibrinogen analysis using Ratnoff's method. In addition, blood sugar, blood urea nitrogen, stool color, fluid intake ard output, and daily weights and temperatures were recorded.

At varying intervals postoperatively the animals were re-explored. Biopsy specimens were obtained from the host livers and from the homografts, and estimates were made concerning the relative sizes of the 2 livers. In addition, operative angiograms were performed in the majority of animals in order to demonstrate the patency of the anastomoses and to obtain general information about the direction and magnitude of venous blood flow. The latter studies were performed with 50 per cent hypaque, by injection into the appropriate portions of the arterial or venous systems.

In addition to the pathologic studies made by open biopsies, complete autopsies were obtained in each instance as quickly as possible after death. All extraneous tissue was dissected free from both livers, and comparative weights of the homograft and the dog's own liver were obtained. The patency of each anastomosis was specifically noted. Tissues were fixed in formol-saline and Carnoy's solution for histologic studies. Sections were routinely stained with hema- toxylin and eosin; Gordon and Sweet's silver impregnation for reticulin; Verhoeff and van Gieson's method for elastic and connective tissue; periodic acid Schiff; Perl's Prussian blue method for iron; and Kutlik's bile stain. Other special stains were used if appropriate.

Three different types of auxiliary homotransplantation were performed:

Group 1. Six homografts were placed in the right paravertebral gutter. The donor vena cava was interposed into the recipient terminal inferior vena cava (Fig. 1B). The hepatic artery was revascularized by means of an end-to-end anastomosis with the right common iliac artery. The end of the homograft portal vein was anastomosed to the side of the recipient's superior mesenteric vein (Fig. 1B), using No. 6-0 silk. The recipient's own portal vein was ligated above the most cephalad tributary, the pancreaticoduodenal vein (Fig. 1B). The splanchnic blood flow was thus directed in a retrograde fashion into the homograft, so that the dog's own liver was supplied only by the hepatic artery.

Group 2. In 6 dogs, a similar operative procedure was carried out except that the ligature was placed on the superior mesenteric vein just below its junction with the splenic vein (Fig. 1C). The venous return from the small intestine was thus diverted through the homograft and the venous flow from the splenic and pancreaticoduodenal areas passed through the recipient animal's own liver. There was consequently a division of the nonhepatic splanchnic flow, both livers receiving a fraction.

Group 3. In 3 animals, portacaval transposition was performed from 3 to 9 months before definitive transplantation. After complete recovery from this preliminary operation, an auxiliary homograft was placed in the same location as in groups 1 and 2 (Fig. 1D). The portal vein was then ligated above the entrance of its highest tributary. This modification was designed to give both livers a complete arterial and venous blood supply. The nonhepatic splanchnic venous flow 


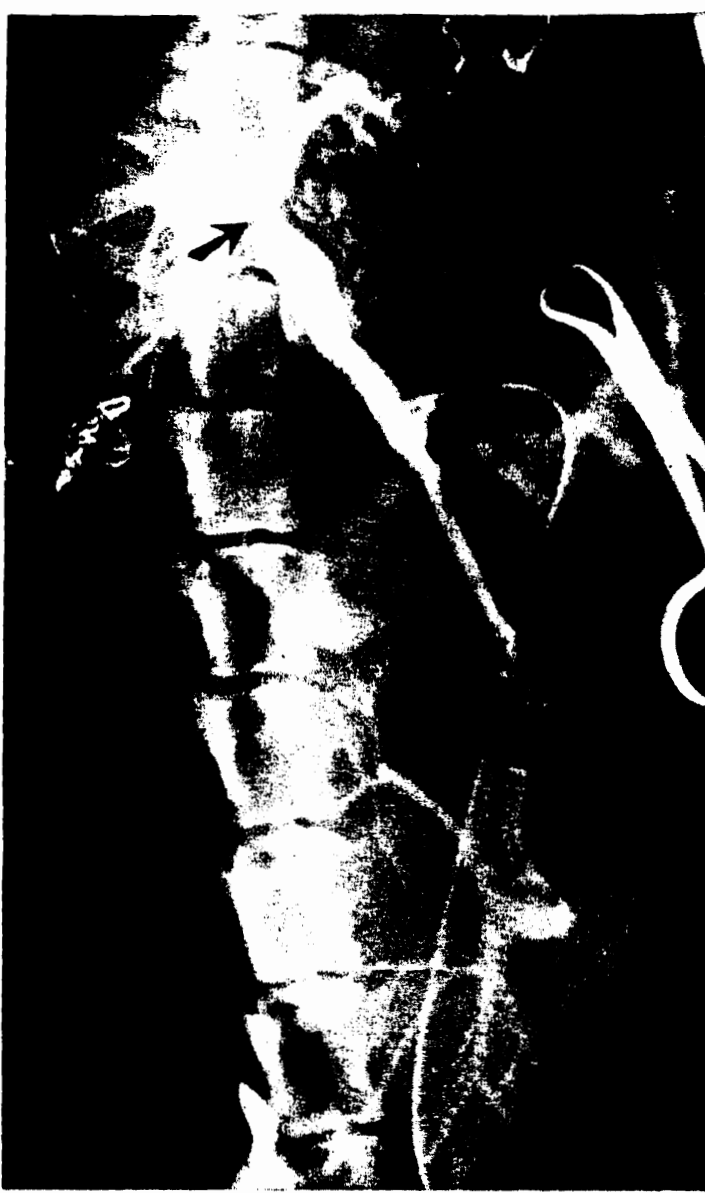

FIG. 2. Operative venous angiogram of dog 5 showing retrograde passage of nonhepatic splanchnic flow through the homotransplanted liver (lower). The ligature around the portal vein is evident (arrow). The dog's own portal system has also filled with dye from collaterals. Note the large size of the homograft compared to the small dimensions of the dog's own liver.

first passed through the homograft and then via the cavaportal anastomosis to the recipient's own liver.

\section{RESULTS IN GROUP 1}

Survival. Six of the 10 animals survived operation. In 3 dogs both livers were in place for 25,28 , and 52 days, after which the dogs died of pneumonia, hemorrhage from a cecal ulcer, and from homograft necrosis, respectively. In the first 2 instances, all vascular channels were found to be patent at autopsy. In the third, the vessels were proved to be patent at angiography 30 days after homotransplantation, but in the subsequent 22 day interval the portal-mesenteric anastomosis clotted. The other 3 dogs were subjected to second stage complete removal of their own livers.

Survival after recipient hepatectomy. Three dogs underwent removal of their own livers (Table I) after 77, 61, and 73 days. At the time of hepatectomy an estimate was made of the relative masses of the 2 livers, and in each instance the homograft was definitely larger than the animal's own liver, which had undergone striking shrinkage. The first of these, dog 5, resumed a full diet within 2 days and was in excellent clinical condition for the remainder of his life. He was re-explored for open hepatic biopsy 43 days later, and 6 days after this procedure was found dead in the cage from a complete evisceration which had occurred during the night.

The second, $\operatorname{dog} 8$, also recovered promptly from pentobarbital anesthesia but died 8 days later from the consequences of wound dehiscence, peritonitis, and massive gastrointestinal hemorrhage from an acute duodenal ulcer.

The third, dog 10, also recovered promptly from hepatectomy, but his subsequent course was complicated by massive ascites. Twenty-seven days after hepatectomy, he was re-explored for biopsy and died the following day.

After hepatectomy, it was noted that the appetite and nutritional requirements for the 2 longest surviving dogs were markedly increased, as much as 5 or 6 times the ordinary diet being consumed daily, despite which weight gain did not occur.

Angiographic studies. In 3 animals, dogs 5, 8 , and 9, the blood supply to the host's own liver and the homograft was investigated by injection of a contrast medium into the terminal aorta and splenic vein. In each, a major portion of the nonhepatic splanchnic venous flow appeared to pass through the homograft, although dye was noted to enter the host liver through collaterals (Fig. 2). All arterial anastomoses investigated were found to be open. In 1 animal in which the portal found quent days

Bio the at rise in in a serum serum lowed ical j the $h$ cent. posto descr prep 
he sub-mesen3 dogs lete re-

Three n livers . At the is made , and in efinitely , which The first Nithin 2 ondition is re-exys later, is found :viscerae night. promptut died $f$ wound : gastroa duode-

promptjsequent $\because$ ascites. omy, he 1 the fol-

that the ients for narkedly the ordidespite , dogs 5 sst's own gated by ) the tereach, a lanchnic Jugh the I to enter (Fig. 2). ted were vhich the

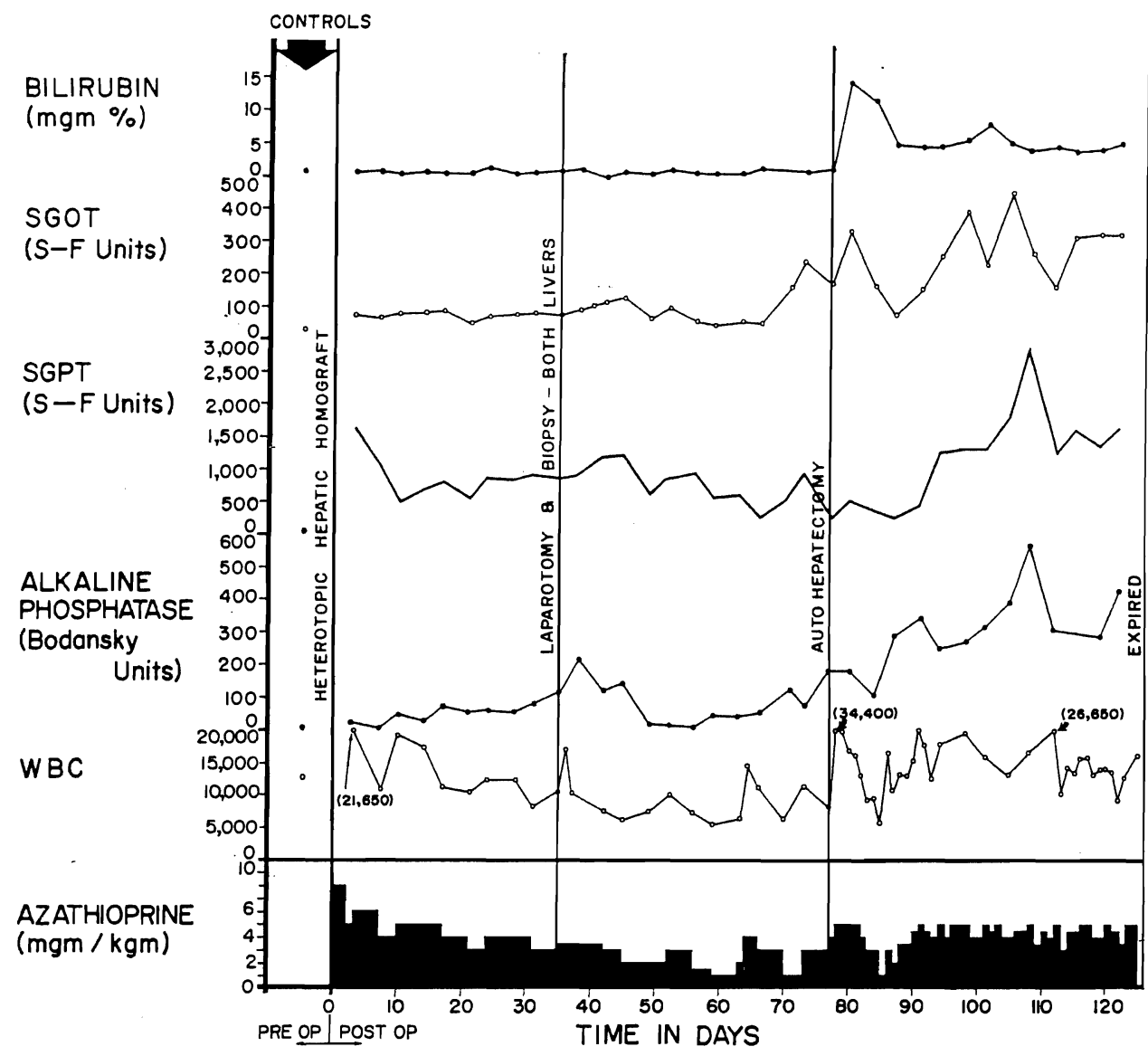

FIG. 3. Clinical course of dog 5 of group 1 series. Note the abrupt bilirubinemia which followed removal of the dog's own liver, autohepatectomy. After autologous hepatectomy, the dog lived for 49 days with sole dependence upon the homograft, ultimately dying as the result of a wound dehiscence and evisceration which followed repeat biopsy.

portal-mesenteric venous anastomosis was found to be patent at angiography, subsequent thrombosis was found at autopsy 22 days later.

Biochemical studies. Following placement of the auxiliary homograft there was a prompt rise in alkaline phosphatase, beginning within a few days after operation (Fig. 3). The serum glutamic oxalacetic transaminase and serum glutamic pyruvic transaminase followed a similar but variable pattern. Chemical jaundice was observed in only $1 \mathrm{dog}$, the highest value being 1.9 milligrams per cent. Fibrinogen tended to rise early in the postoperative course as has been previously described (12) with the Welch-Goodrich preparation.
Following removal of the animal's own liver, a sharp increase in bilirubin was noted in all 3 dogs during the first few days of total dependence upon the homograft, to levels as high as 14.5 milligrams per cent (Fig. 3). The stools became temporarily clay-colored and the urine deepened in color. Despite this, these animals appeared to be in good general condition, and within 1 week the jaundice began to recede in all (Fig. 3), stabilizing between 4 and 7.6 milligrams per cent at the same time that bile reappeared in the stools. Hypoglycemia was not observed. Rises of alkaline phosphatase, serum glutamic oxalacetic transaminase and serum glutamic pyruvic transaminase occurred after autologous hepatectomy with 


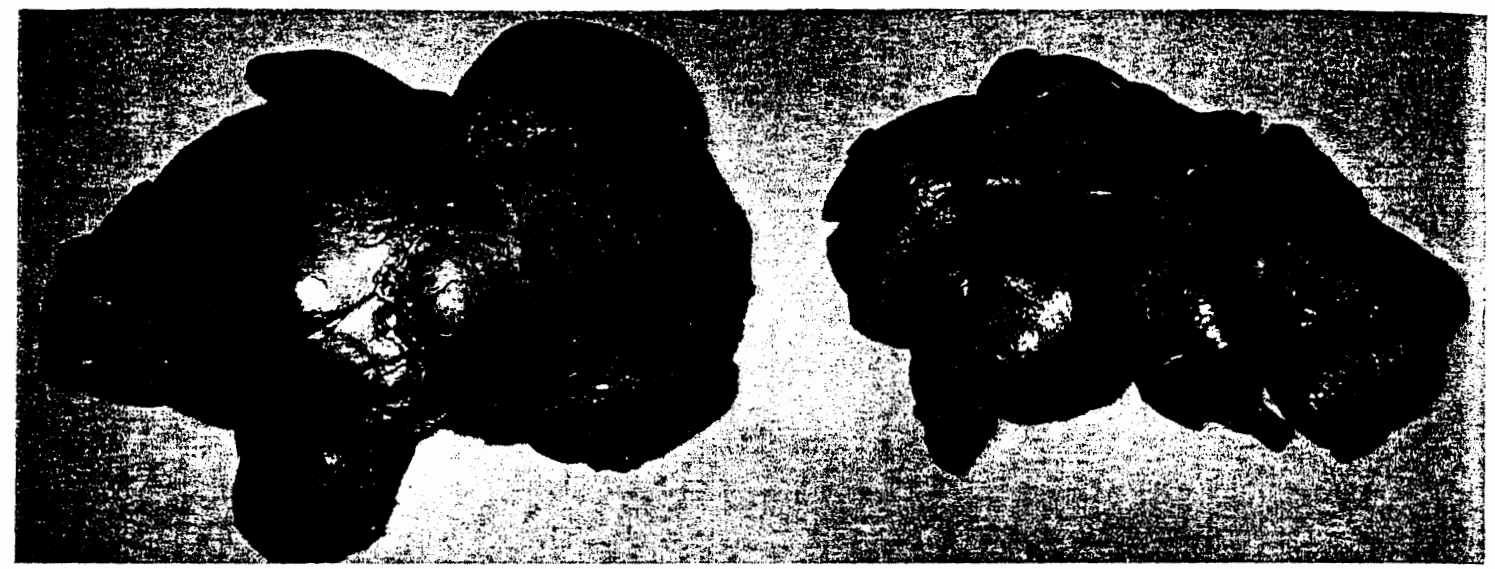

FIG. 4. Auxiliary liver homograft, left, compared to the animal's own liver, right, in dog 8 of group 1 series. The homograft was obtained at autopsy, and the animal's own liver was removed 8 days earlier. The weight of the homograft was more than twice that of the autologous hepatic tissue

subsequent partial return toward, but never to, normal (Fig. 3). The stools of these animals frequently were observed to contain poorly digested food, the excreta resembling the dog food which had been recently ingested. Stools were voluminous. Analysis of the diet and stool for fat demonstrated almost complete lack of fat absorption in the 2 longest survivors.

Gross pathologic observations. The weights of the animal's own liver and those of the homograft are listed in Table I. In each instance, the homograft weighed more than the host liver, despite the fact that the donor animals were all smaller than the recipients. In 3 animals, dogs 5,8 , and 10, the comparative weights of the autologous liver and the homograft were not obtained simultaneously, the interval from hepatectomy to death being 8 to 49 days. In the other 3, both weights were obtained at autopsy.

The animal's own liver in each instance was grossly normal except for its small size
(Fig. 4). The homografts in 5 instances appeared to be relatively normal (Fig. 4) except for some increased firmness. In the 1 dog in which thrombosis of the portal system occurred following angiography, the homograft was nodular and appeared cirrhotic and partially necrotic at autopsy.

Microscopic findings in host liver. Samples of host liver were examined microscopically $25,26,28,30,35,51,52,61,63,73$, and 77 days following high ligation of the portal vein and hepatic homotransplantation. Five of the 11 specimens were obtained either at open biopsy or at the time of removal of the host liver, while the others were collected at autopsy.

In the earlier samples there was necrosis of a variable number of the cells in the central zones of the hepatic lobules (Fig. 5A). In a few of the specimens this was associated with fat droplets in the cytoplasm of the liver cells in the other zones. The small branches of the portal'vein were distended with blood.

TABLE I.-RESULTS IN GROUP 1

$\begin{array}{cccccccc}\begin{array}{c}\text { Dog } \\ \text { No. }\end{array} & \text { Weight of } & \begin{array}{c}\text { Weight of } \\ \text { recipient, }\end{array} & \begin{array}{c}\text { Total } \\ \text { survival, } \\ \text { days }\end{array} & \begin{array}{c}\text { Removal } \\ \text { host } \\ \text { liver }\end{array} & \begin{array}{c}\text { Sgm. } \\ \text { hepatectomy, } \\ \text { days }\end{array} & \begin{array}{c}\text { Weight of } \\ \text { homograft at } \\ \text { autopsy, gm. }\end{array} & \begin{array}{c}\text { Weight of hosl } \\ \text { liver at autopsy or } \\ \text { hepatectomy, gm. }\end{array} \\ 2 & 14.1 & 15.2 & 28 & \text { No } & \text { Not done } & 325 & 322 \\ 4 & 14.5 & 19.5 & 25 & \text { No } & \text { Not done } & 380 & 306 \\ 5 & 15.4 & 18.2 & 126 & \text { Yes } & 49 & 656 & 225 \\ 8 & 18.6 & 20.5 & 69 & \text { Yes } & 8 & 478 & 211 \\ 9 & 18.2 & 18.6 & 52 & \text { No } & \text { Not done } & 440 & 300 \\ 10 & 20.0 & 22.9 & 101 & \text { Yes } & 28 & 492 & 310\end{array}$



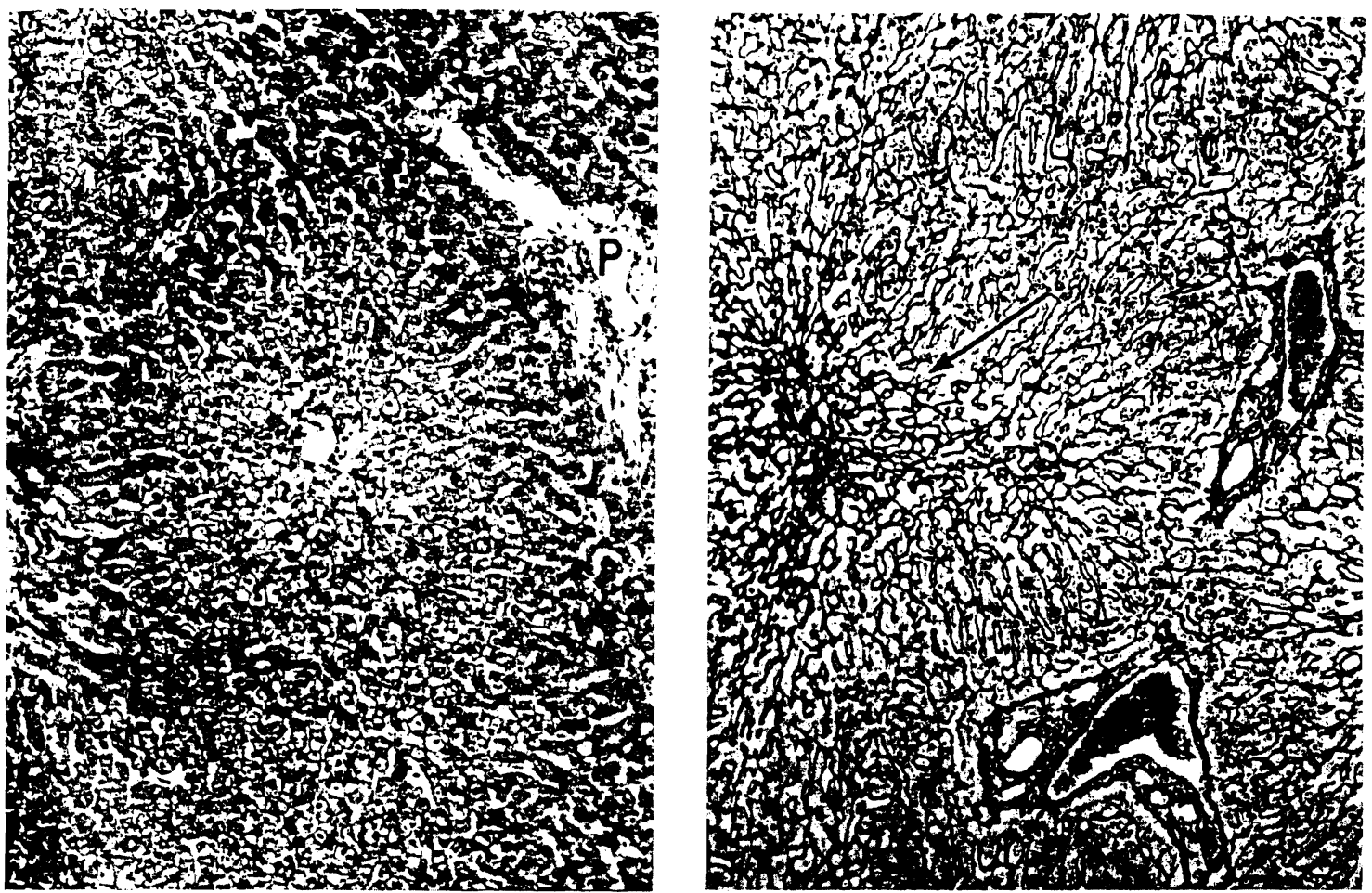

Frg. 5. Biopsies of their own livers from 2 dogs in group 1: A, left, 35 days after operation (dog 5). There is centrizonal necrosis of the liver cells; $P$, portal tract. Hematoxylin and eosin, $X 65$. B, right, 51 days after operation ( $\operatorname{dog} 10$ ). The centrilobular reticulin has collapsed (arrow). Reticulin, $\times 90$ sically nd 77 portal Five her at of the :ted at

əcrosis e cen-

Large amounts of hemosiderin were present in the Kupffer cells and within macrophages which lay in the portal tracts.

In the samples collected after the thirtyfifth postoperative day there was centrizonal atrophy of the hepatic cells with collapse of the reticulin network immediately adjacent to the central vein (Fig. 5B). The bile ducts and hepatic arteries were normal. There were no infiltrating lymphoid cells. Iron pigment was still present.

Microscopic findings in the auxiliary homografts. Samples of the homografts were examined microscopically 25 to 126 days following transplantation, either at open biopsy, at the time of removal of the host's own liver, or at autopsy. Only autopsy tissues were available from dogs 2 and 4, 28 and 25 days respectively after transplantation. Dog 9 had a biopsy 30 days after homotransplantation; the portal venous anastomosis subsequently thrombosed, and the dog died
52 days after the original operation. Serial specimens were available for the other 3 dogs before and after removal of the host's own liver and at subsequent autopsy. These were obtained from dog 5 after 35, 63, 120, and 126 days. In dog 8 the tissues were taken after 26, 61, and 69 days. In dog 10 the specimens were obtained after 51,73 , 100 , and 101 days. In dog 9 in which thrombosis of the portal system occurred after angiography, there was widespread centrizonal necrosis accompanied in several areas by necrosis of whole lobules and collapse of the reticulin framework.

In 4 of the other 5 liver transplants, there was cellular infiltration (Fig. 6A). In dog 2, which lived for 28 days, this affected only the small portal tracts, but in the others the adventitia of the central hepatic veins was also involved. The infiltrate consisted of small and medium-sized lymphocytes, plasma cells, and larger cells with scanty pyroni- 


\section{Surgery, Gynecology \& Obstetrics · July 1965}
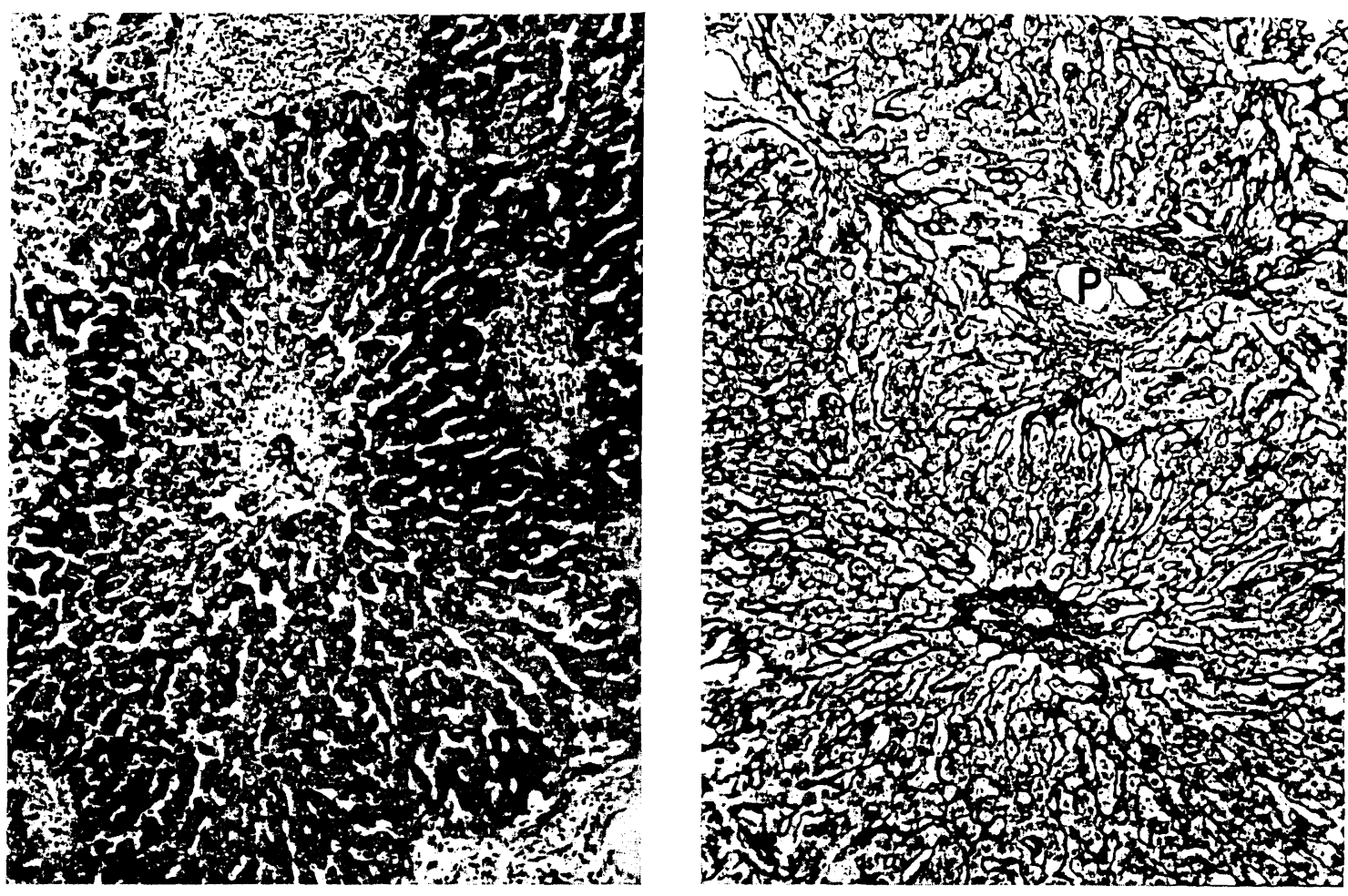

FIG. 6. Biopsies of hepatic homografts from 2 dogs of group 1: A, left, 35 days after transplantation (dog 5). The portal tracts contain many infiltrating cells. The wall of the central hepatic vein is thickened and lightly infiltrated with cells. Hematoxylin and eosin, $\times 65$. B, right, 61 days after transplantation $(\operatorname{dog} 8)$. There is a dense accumulation of reticulin and collagen fibers around and within the wall of the central hepatic vein; $P$, portal tract. Reticulin, $\times 65$.

nophilic cytoplasm, large nuclei, and prominent nucleoli. The only unaffected liver was that of dog 4 which lived for 25 days. There was a tendency as time went by for the cellular infiltration to diminish in intensity and for plasma cells to predominate. For example, in dog 5 in which the infiltrate was very heavy at 35 days, there was a slight diminution by 63 days, but by 120 days invading cells were far less frequent and were then mostly plasma cells. A similar striking decrease was seen in $\operatorname{dog} 8$ in which the biopsy taken at 61 days showed much less cellular infiltration than was present at 26 days.

When cellular infiltration involved the central hepatic veins, there was swelling of the endothelial cells and, in 2 of the dogs, fibrinoid necrosis of the venous wall was present. In biopsies, these veins were the site of fibrous intimal thickening and ac- cumulation of reticulin and collagen fibers around the adventitia of the affected vessels (Fig. 6B). Fibrous occlusion of some central veins was found in dogs 5 and 8 .

A few foci of acute fibrinoid necrosis were seen in the walls of small hepatic arteries in $\operatorname{dog} 2$; in the other dogs these vessels were normal. The sinusoids were distorted in the central zones of the liver from $\operatorname{dog} 2$, and in this same animal the Kupffer cells were loaded with hemosiderin. In the other 4 homografts the sinusoids were normal and the Kupffer cells contained very little iron pigment. The portal veins and lymphatics were normal in all the homografts.

In the 1 animal, dog 2 , which died from massive gastrointestinal hemorrhage there was necrosis of liver cells in the central zones of the lobules. In the other homotransplants, the liver cells appeared normal. 

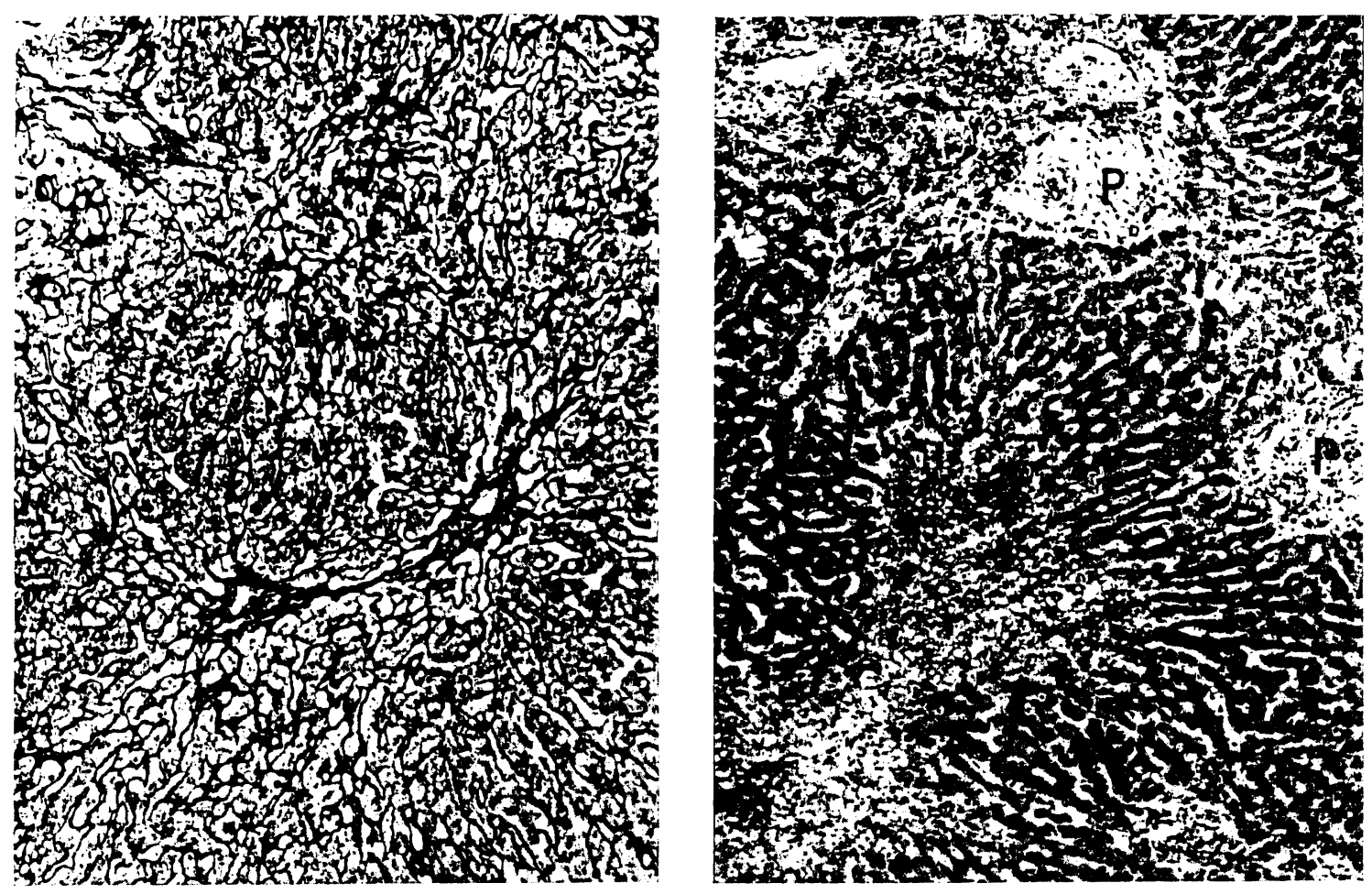

Fic. 7. Two canine hepatic homografts: A, left, 120 days after transplantation (dog 5 group 1). A band of reticulin fibers links 2 central veins. Reticulin, $\times 65$. B, right, 52 days after transplantation (dog 18 group 2). Centrizonal liver cell necrosis and hemorrhage is combined with cellular infiltration of the portal tracts $(P)$. Compare with Figure 6A. Hematoxylin and eosin, $\times 65$.

In the biopsies from dogs 5 and 10 at 120

\section{RESULTS IN GROUP 2}

Survival. Six of the 10 dogs survived the immediate postoperative period. Two of the 6 remaining dogs died spontaneously. The first lived for 41 days and died 4 days after biopsy and direct inspection of the arterial anastomosis. At operation, a needle was inserted into the hepatic artery for pressure determination. At postmortem examination the vessel was found to have a fresh thrombosis. Pneumonia was also present. The other animal died at 46 days of bilateral pneumonia.

The other 4 animals were sacrificed from 50 to 58 days after homotransplantation, usually following biopsy and angiography.

Angiographic studies. Four of the 6 dogs had angiograms. In these 4 , the vascular anastomoses were patent and blood flow above the mesenteric ligature was demonstrated to the animal's own liver (Fig. 8A). Flow below the ligature passed to the homograft (Fig. 8B).

Biochemical studies. These were essentially the same as in group 1 (Fig. 9). In none of the dogs did jaundice develop. No second 
Surgery, Gynecology \& Obstetrics · July 1965

TABLE II.-RESULTS IN GROUP 2

\begin{tabular}{lc}
$\begin{array}{lc}\text { Dog } \\
\text { No. }\end{array}$ & $\begin{array}{c}\text { Weight of } \\
\text { donor, kgm. }\end{array}$ \\
14 & 14.7 \\
15 & 15.6 \\
16 & 15.0 \\
18 & 10.9 \\
19 & 11.7 \\
20 & 15.4 \\
\hline *acrificed &
\end{tabular}

stage host hepatectomies were carried out.

Gross pathologic observations. In dog 14 the portal vein was found at autopsy to be thrombosed. In this experiment, the dog's own liver weighed 390 grams, and the homograft weighed 285 grams.

In the other 5 animals, in which the portal branches were patent, there was variation in the sizes of the homograft and the animal's own liver (Table II). In dog 20, the homograft.was distinctly larger, being 346 grams compared to 262 grams for the host liver. In the other 4 , the host liver was larger, but in 1 of these, dog 15, the difference was slight, the homograft weighing 400 grams compared to 475 grams for the autologous organ. In the other 3 , the disparity was greater, the homografts weighing 158 , 150 , and 118 grams compared to autologous liver weights of 265,358 , and 485 grams, respectively (Table II).

Microscopic studies in host liver. Samples of host liver were examined microscopically $37,39,41,46,49,50,52,55,57$, and 58 days following ligation of the superior mesenteric vein and hepatic homotransplantation. Six of the 12 specimens were obtained at open biopsy, while the others were collected at autopsy.

Four of the livers were normal. The liver from dog 18, which had suffered a serious blood transfusion reaction, showed congestion of the sinusoids in the centers of the lobules and necrosis of liver cells adjacent to the central veins which were congested. Inspissated bile was present in some of the centrilobular canaliculi. In the greatly atrophied liver from dog 20 there were the same changes of centrizonal atrophy of the hepatic cells with collapse of the reticulin network adjacent to the central vein as were seen in the host livers of group 1 .

Microscopic findings in the auxiliary homografts. Samples of the homografted livers were examined at the same times after transplantation as were specimens from the dogs' own livers. In 2 of the livers large vessels were thrombosed. The biopsy at 39 days from dog 14 showed inspissated bile in the centrilobular canaliculi and large deposits of hemosiderin in the Kupffer cells, but no other abnormalities. Seven days later, after portal vein thrombosis, there was extensive centrizonal hemorrhage and necrosis of liver cells. In dog 15, hepatic artery thrombosis produced widespread hemorrhagic necrosis of the liver.

Of the other 4 homotransplants, the 3 livers which underwent atrophy all showed centrizonal necrosis of liver cells (Fig. 7B). In dog 16 this was present in the first biopsy taken at 37 days and at the time the liver cells in the middle and peripheral zones contained many fat deposits in their cytoplasm. By 55 days the necrotic process had spread so that in many areas only the periportal liver cells remained. In dogs 18 and 19 the process was not so severe. The liver from $\operatorname{dog} 20$ showed no centrilobular necrosis of liver cells.

Infiltration with lymphoid cells was present around the smaller branches of the portal vein and around the central veins in these 4 hepatic homotransplants. In dog 16 the number of infiltrating cells was at first large, but in the biopsy taken at 57 days this infiltration was greatly diminished. Slightly fewer cells were present in dogs 18 and 19, and very few were present in dog 20.

As in group 1, cellular infiltration around 

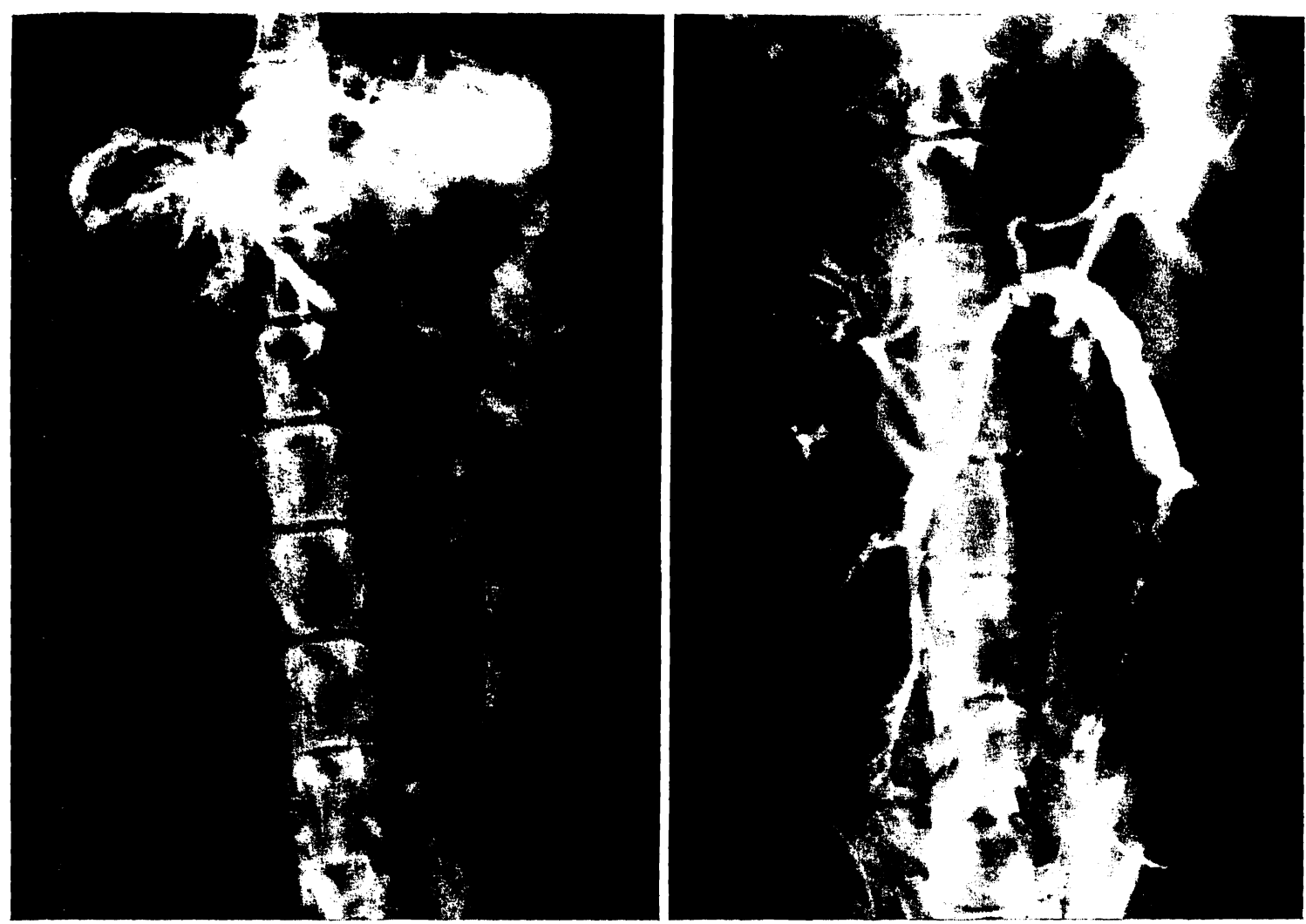

FIG. 8. Operative angiograms on dog 20 of group 2. A, left, Contrast medium injected into the splenic vein passes through the animal's own liver. B, right, Contrast material injected through a distal mesenteric vein tributary passes through the homografted liver. Note the relatively large size of the homograft compared to the animal's own liver. This impression was confirmed at autopsy at which the homograft weighed 346 grams and the autologous liver, 262 grams.

the central veins was accompanied by swelling of endothelial cells and in 2 instances by focal fibrinoid necrosis of the vein wall. Perivenous fibrosis and occlusion of the lumina of the central veins subsequently occurred in $\operatorname{dog} s 16$ and 19.

Portal veins were normal. There were foci of acute fibrinoid necrosis in the wall of a small hepatic artery (Fig. 10) and eccentric intinal fibrous thickening in another in 1 homografted liver at 50 days, dog 19. The sinusoids were interrupted in the liver lobules of the 3 animals showing centrilobular necrosis. Hemosiderin was present in ty larce amounts in both Kupffer cells and in 19, I marrophages lying in the portal tracts in the livers from dogs 16 and 18. The lymind
There was collapse of the reticulin network of the lobules adjacent to the central vein in the 3 dogs which showed centrilobular loss of liver cells. In the specimens from dogs 18 and 19 at 52 and 50 days respectively, fibrous and reticulin bands linked adjacent areas of fibrosis around central veins. In dog 16 there was complete collapse of the reticulin framework wherever necrosis of all the liver cells in a lobule had occurred. The lobular architecture was undisturbed in dog 20.

In the homograft from dog 16, many of the small bile ducts were severely damaged, and this was accompanied by accumulations of bile pigment in the surviving liver cells. Proliferation of the smaller bile ducts was present in the homograft from dog 19. 


\section{Surgery, Gynecology \& Obstetrics · July 1965}

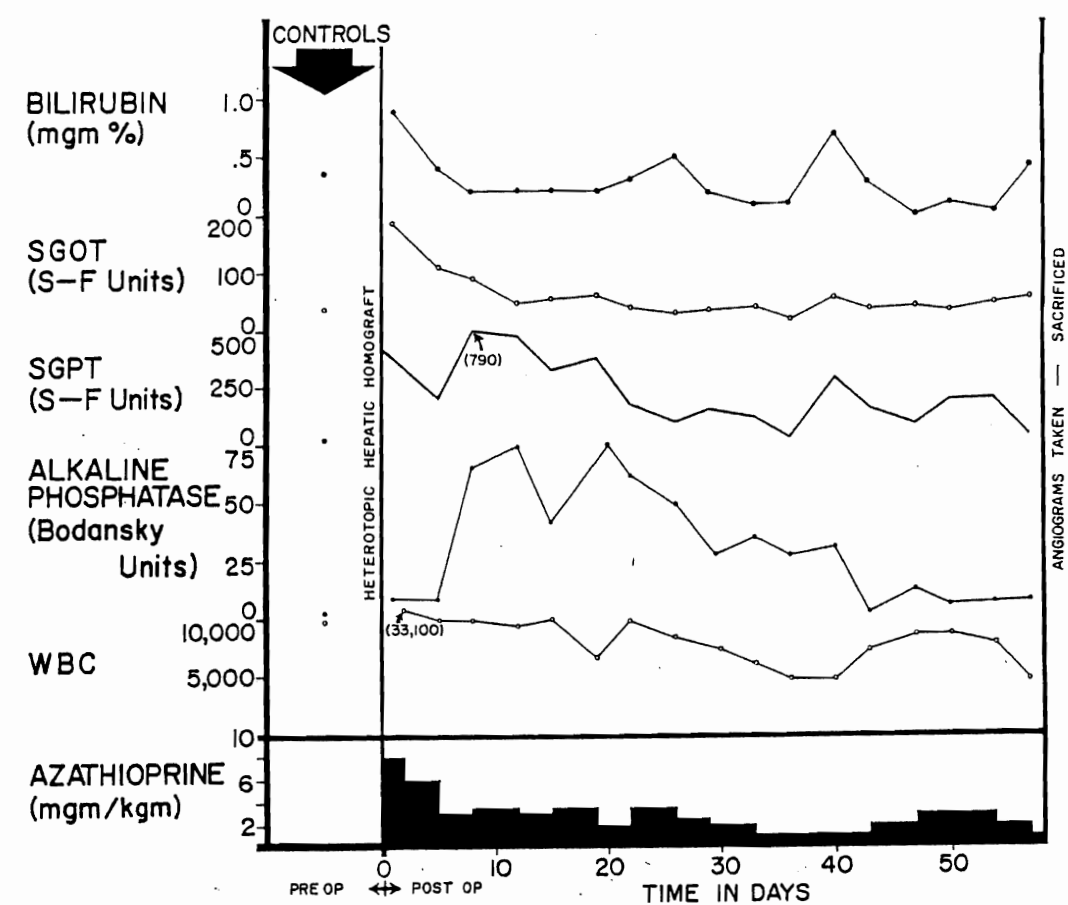

FIG. 9. Clinical course of dog 20 of group 2. The animal is the same one as shown in Figure 8.

In the other 2 animals, the bile ducts and canaliculi appeared normal.

\section{RESULTS IN GROUP 3}

Survival. A completely satisfactory technical result was not obtained in any of the 6 experiments. Three dogs died immediately after operation. Late thrombosis of the homograft vena cava was observed in 2 of the remaining dogs, and late thrombosis of the portal vein in the third animal.

\section{DISCUSSION}

Since the description of auxiliary hepatic homotransplantation by Welch and Goodrich and their associates, a number of studies of this preparation have been published. The assumption has been generally made that the changes observed in the grafted tissue were solely due to immunologic rejection. Virtually all of this earlier work was carried out in canine recipients which were not treated with immunosuppressive agents, including Welch's original studies and those subsequently reported by
Sicular and Mehrez and their associates. Under these circumstances, the influence of physiologic factors upon the outcome was difficult to delineate because the full vigor of homograft rejection destroyed the transplanted tissue within a few days.

The only reports in the literature of auxiliary homotransplantation to recipients which were receiving immunosuppressive drug therapy were published from this laboratory $(12,13)$. In dogs, it was found that the behavior of such secondarily placed homografts was significantly different from that of orthotopic homografts in similariy treated animals in that the auxiliary homografts markedly diminished in size within a few weeks after operation. The present study provides strong evidence that this difference in behavior in the two types of homografts is not solely of immunologic etiology. Rather, the auxiliary homograft shrinkage appears to be due to deprivation of nonhepatic splanchnic flow in the presence of the recipient animal's own liver. When, as in the present study, the situation is reversed so 
that the nonhepatic splanchnic flow is directed initially through the homograft, a similar shrinkage is observed in the dog's own liver. These experiments have made clear at least one physiologic requirement which must be observed in revascularization of the auxiliary liver homograft. Because of the apparent competition for nutritional substrate which occurs in the presence of 2 livers, the homografted organ must receive its portal supply directly from the alimentary venous return.

The histologic changes in the recipient's own liver are of great interest in the dogs of group 1. During the entire course of these animals, serial biochemical changes were described, but it was, of course, impossible to be sure if these resulted from homograft injury or from damage to the autologous liver. The small size of the host livers in these animals, in which the splanchnic flow was diverted completely through the homograft, was apparently due to centrizonal necrosis with collapse and condensation of the reticulin in the center of the lobule. These changes are similar to those described by Mann and his associates more than 30 years ago, after the performance of Eck fistula in dogs, an experiment in which immunologic factors were absent. In the host livers of the present study, there was nothing to suggest that they had been damaged by a graft against host reaction; lymphoid cell infiltration and arterial lesions were not seen. Also, although it is known that azathioprine can cause hepatic damage, the normal state of the majority of the dogs' own livers in group 2 makes it improbable that chronic drug toxicity was an important factor. It is interesting that the only host liver in group 2 which showed severe centrilobular lesions and general atrophy came from dog 20 in which the homograft had retained its full size.

The same substrate starvation, which appeared to have caused this damage to the host liver, seemed to have an even more adverse effect upon the homograft, particularly when judged by the gross characteristic

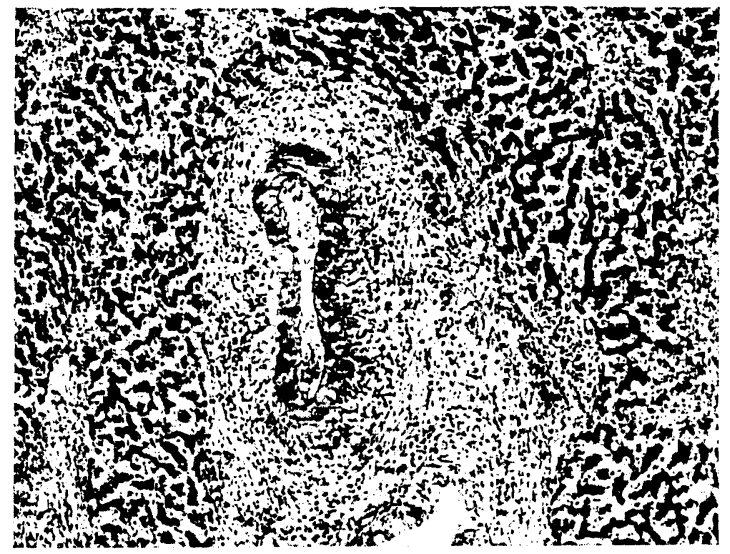

Fig. 10. Homografted liver 50 days after transplantation (dog 19 group 2). In the portal tract a branch of the hepatic artery shows fibrinoid necrosis of its wall. The surrounding connective tissue is infiltrated with cells. At the right of the photomicrograph there is centrizonal necrosis of liver cells. Hematoxylin and eosin, $\times 50$.

and weight of the competing livers. In the animals of group 2, in which the two livers shared the nonhepatic splanchnic flow, 5 of the 6 homografts were smaller than the respective host livers and in the 3 most severely atrophied transplants, in this series, the same centrizonal necrosis was very prominent. Because the homograft is subject to the injury of rejection, the resultant histologic alterations cannot be so clearly assigned a metabolic etiology, however, especially since centrizonal necrosis has also been described as characteristic in the rejecting orthotopic hepatic homograft, either with or without use of immunosuppressive drugs $(11,13)$.

Long survival of some of the animals in the present study permitted analysis of the pathologic findings at a much later time than has previously been possible and allowed a serial view of the histologic changes. In the first 2 experimental groups, the majority of the homotransplanted livers showed evidence of a cellular homograft reaction with lymphoid cell infiltration around the small branches of the portal vein and around the central hepatic veins. In all of these homotransplants that were sequentially biopsied, the infiltration tended to decrease with time, a process which was not appre- 


\section{Surgery, Gynecology \& Obstetrics · July 1965}

ciably hastened following removal of the host's own liver.

Late in the course, centrilobular fibrosis and phlebosclerosis and, to a much less extent, periportal fibrosis were seen. In the longest survivors, these changes had progressed to the development of fibrous bands which linked some of the affected central zones. In many ways, the evolution of these structural alterations resembled that of venoocclusive disease such as that described by Bras and his associates. Another late finding was the loss of small bile ducts with consequent accumulation of inspissated bile in the centrilobular canaliculi. Fibrinoid necrosis of branches of the hepatic artery was rare.

It is probable that these late changes occurred as the result of the action of circulating and cell-bound antibodies produced by the host, but at present it is still difficult to distinguish immunologically mediated lesions from those which result from mechanical or other factors. The central phlebosclerosis and surrounding fibrosis could, for example, have been the result of a mild chronic degree of early postoperative outflow block. As more long term survivals from canine hepatic homotransplantation are studied, these questions concerning the late pathologic findings in the homografts should be resolved.

\section{SUMMARY}

Auxiliary hepatic homotransplants were performed in dogs, the second liver being placed in the pelvis of the recipient. In each instance, the hepatic artery was revascularized from the external iliac artery. In 6 dogs, the portal vein of the homograft was anastomosed to the superior mesenteric vein and the proximal portal vein then ligated; the splanchnic blood flow was directed in a retrograde fashion through the homograft, and the dog's own liver was left supplied solely by the hepatic artery. In another 6 dogs, a similar operation was performed and venous revascularization carried out so that the nonhepatic splanchnic flow of the re- cipient was shared by both the host liver and the homograft.

In those animals in which the nonhepatic splanchnic flow was diverted through the auxiliary liver (group 1), the homograft retained its full size and there was marked shrinkage of the host's own liver. Histologically, the loss of size observed in the host liver appeared to be due to centrizonal necrosis with collapse of the reticulin which was most pronounced around the central vein.

In those animals in which the host liver and the homograft shared the nonhepatic splanchnic flow, there was variable shrinkage of the homograft with retention of normal size in all but 1 of the host livers. These findings appear to have defined an important physiologic requirement for auxiliary homotransplantation. Because of the apparent competition for nutritional substrate, which seems to occur in the presence of 2 livers, the homografted organ must receive its venous inflow directly from the alimentary venous return.

Of even greater importance than the preservation of homograft morphologic integrity is the retention by the optimally vascularized auxiliary liver of the ability to sustain life, as demonstrated by the ultimate test imposed by removal of the host's own liver. Despite the fact that 5 of the 6 homografts in the first group of animals had histologic evidence of cellular rejection, autologous hepatectomy in 3 of these dogs was followed by survival of 8,28 , and 49 days with total posttransplant survival of 69,101 , and 126 days.

Survival in these experimental animals was greater than any previously reported hepatic homotransplantation and permitted observations of late pathologic changes. These included phlebosclerosis of the central veins, perivenous fibrosis of the portal and central veins, the development in the 2 longest survivors of fibrous bands joining. some of the affected central zones one to another, and the disappearance in the same 2 dogs of the small intrahepatic bile ducts 
Marchioro et al.: REQUIREMENTS FOR AUXILIARY LIVER HOMOTRANSPLANTATION 3

with the development of intrahepatic cholestasis. In the dogs in which serial biopsies were carried out, the findings of cellular rejection were demonstrated in every instance to diminish with the passage of time, the first histologic demonstration of the reversibility of rejection in hepatic homografts.

\section{REFERENCES}

1. Bodansky, A. Notes on the determination of inorganic phosphate and serum phosphatase activity. J. Biol. Chem., 1937, 120: 167.

2. Bras, G., Jelliffe, D. B., and Stuart, K. L. Venoocclusive disease of the liver with non-portal type of cirrhosis occurring in Jamaica. Arch. Path., Chic., 1954, 57: 285.

3. ChIld, C G. III Bark, D. Holswade, G. R., and HARRISON, C. S. Liver regeneration following portacaval transposition in dogs. Ann. Surg., 1953, 138: 600.

4. Goodrich, E. O., Welch, H. F., Nelson, J. A., BEEGHER, T. A., and WelCh, C. S. Homotransplantation of the canine liver. Surgery, 1956, 39: 244.

5. MAlloy, H. T, and Evelyn, K. A. The determination of bilirubin with the photoelectric colorimeter. J. Biol. Chem., 1937, 119: 481.

6. ManN, F. C., Fishback, F. C., Gay, J. G., and Green, C. F. Experimental pathology of the liver-
III, the effect of diverting the portal blood on the restoration of the liver after partial removal. Arch. Path., Chic., 1931, 12: 787.

7. Mehrez, I. O., Nabseth, D. C., Kekis, B. P., Apostolou, K., Gottlieb, L. S., and Deterling, R. A. Homotransplantation of the canine liver; a new technic. Ann. Surg., 1964, 159: 416.

8. Ratnoff, O. D., and Menzie, C. New method for determination of fibrinogen in small samples of plasma. J. Laborat. Clin. M., 1951, 37: 316.

9 Sicular, A., Dreiling, D. A., Paronetto, F., and KARK, A. E. Studies of rejection of the homotransplanted canine liver. Surgical Forum; Clinical Congress 1961. Vol. XII, p. 202. Chicago: American College of Surgeons, 1961.

10. Strma-Frankel. Sigma Technical Bulletin. May 1963, 565.

11. Starzl, T. E., Kaupp, H. A., Brock, D. R.. Linman, J., and Moss, W. T. Studies on the rejection of the transplanted homologous dog liver. Surg. Gyn. Obst., 1961, 112: 135.

12. Starzl, T. E., Marchioro, T. L., Huntley, R. T., Rifkind, D., Rowlands, D. T., JR., Dickinson, T. C., and WADDELL, W. R. Experimental and clinical homotransplantation of the liver. Ann. N. York Acad. Sc., 1964, 120: 739.

13. Starzl, T. E., Marchoro, T. L., Rowlands, D. T., JR., Kirkpatrick, C. H., Wilson, W. E. C., RIFKIND, D., and WADDELI, W. R. Immunosuppression after experimental and clinical homotransplantation of the liver. Ann. Surg., 1964, 160: 411.

14. WELCH, C.S. A note on transplantation of the whole liver in dogs. Transpl. Bull., 1955, 2: 54. 